\title{
Nível de Informação e Comportamento Preventivo de Cirurgiões- Dentistas e Usuários das Unidades Básicas de Saúde do Programa Saúde da Família de Aracaju-SE a Respeito de Câncer Bucal
} Level of Knowledge and Preventive Behavior of Surgeon-Dentists and Users of Basic Healthcare Units from the Family Healthcare Program in Aracaju-SE Regarding Oral Cancer

Nivel de Información y Comportamiento Preventivo de Cirujanos Dentistas y Usuarios de las Unidades Básicas de Salud del Programa Salud de la Familia en Aracaju-SE con Respecto al Cáncer Bucal

\author{
Allan Ulisses Carvalho de Melo', Marize Raquel Diniz da Rosa²
}

\section{Resumo}

O câncer bucal é um problema de saúde pública no Brasil, não somente em virtude das altas taxas de incidência e prevalência, mas principalmente devido aos baixos índices de sobrevida, apesar dos avanços na terapêutica oncológica. Conhecer o nível de informação dos cirurgiôes-dentistas e dos usuários dos serviços de saúde a respeito do câncer de boca e como eles se comportam preventivamente em relação a essa doença é de grande relevância para o planejamento, execução e avaliação de políticas públicas de saúde voltadas para as neoplasias malignas bucais. Assim, o objetivo deste estudo foi investigar o nível de informação e de comportamento preventivo dos cirurgiōesdentistas do Programa Saúde da Família (PSF) e dos usuários atendidos nas Unidades Básicas de Saúde (UBSs) do PSF de Aracaju-SE, a respeito do câncer bucal. Foram realizadas entrevistas estruturadas com usuários e cirurgiōesdentistas das UBSs do PSF, utilizando-se roteiros de entrevistas construídos para este fim. A partir da análise das respostas, os participantes do estudo eram classificados de acordo com um escore em baixo, médio e alto nível de informação e de comportamento preventivo. Foram entrevistados 489 usuários, sendo 383 mulheres $(78,3 \%)$ e 106 homens $(21,7 \%)$, predominando os jovens, com a média de idade igual 33,7 anos. Participaram 47 cirurgiõesdentistas, sendo 40 mulheres $(85,1 \%)$ e sete homens (14,9\%), com idades variando entre 38 e 59 anos, com média de idade igual 47,4 anos. Em relação ao nível de informação, 252 (51,5\%) usuários das UBSs do PSF de Aracaju apresentaram médio nível e 325 (65,9\%) expressaram alto nível de comportamento preventivo sobre câncer de boca. Os usuários desconheciam ou possuíam informações inadequadas sobre fatores de risco, apresentação clínica do câncer bucal e autoexame de boca, além de acharem que o câncer bucal era contagioso. Por outro lado, forneceram repostas adequadas sobre como proceder para perceber lesão na própria boca. Evitavam fatores de risco como tabagismo e etilismo; consultavam regularmente profissional de saúde; não demorariam a buscar auxílio profissional caso notassem alteraçōes bucais; e cerca da metade fizeram autoexame de boca. Em relação ao nível de informação, 33 (70,2\%) cirurgiōes-dentistas das UBSs do PSF de Aracaju apresentaram médio nível de informação e 26 (55,3\%) demonstraram baixo nível de comportamento preventivo. Os cirurgiōes-dentistas

${ }^{1}$ Autor

${ }^{2}$ Orientadora

Dissertação apresentada no Programa de Pós-Graduação em Odontologia da Universidade Federal da Paraíba para obtenção do título de mestre em Odontologia, João Pessoa (PB), Brasil - 2006.

Área de concentração: Diagnóstico Bucal. Agência de Fomento: Coordenação de Aperfeiçoamento de Pessoal de Nível Superior (CAPES).

Endereço para correspondência: Allan Ulisses Carvalho de Melo. Avenida Acrísio Cruz, 147- Apto. 401. Salgado Filho - Aracaju (SE), Brasil. CEP: 49020-210.

E-mail: aucmelo@yahoo.com.br 
desconheciam ou possuíam informaçoes inadequadas sobre lesões cancerizáveis e tipo histológico mais prevalente. No entanto, forneceram informações corretas sobre localização, apresentação clínica, fatores de risco e ações para prevenção/diagnóstico precoce do câncer bucal. Os cirurgiōes-dentistas não faziam um exame clínico adequado e não realizavam educação em saúde sobre câncer bucal em mais de $50 \%$ dos pacientes. Com base nesses dados, recomendou-se a execução de programa de educação permanente para os cirurgiôes-dentistas do PSF de Aracaju e ações de educação em saúde para a população atendida nas UBSs do PSF a respeito do câncer bucal. 